\title{
Patient opinion of lower urinary tract symptoms and their treatment: a cross-sectional survey in Hong Kong public urology clinics
}

\author{
LY Ho *, CK Chan, Peggy SK Chu
}

\section{A B S T R A C T}

Introduction: Lower urinary tract symptoms collectively represent a common condition among ageing men. There are, however, limited data on the frequency of individual symptoms in patients who seek specialist care. We conducted a multinational survey in South-East Asia to evaluate patients' self-reported prevalence, bother, treatment, and treatment satisfaction of four lower urinary tract symptoms namely, urgency, nocturia, slow stream, and post-micturition dribble. This report presents the analysis of the Hong Kong subpopulation.

Methods: This cross-sectional survey involved adult men aged over 18 years who attended a urology out-patient clinic because of lower urinary tract symptoms. A structured questionnaire, translated and validated in the local languages, was selfadministered by patients.

Results: Of 1436 respondents surveyed in the region, 225 were from Hong Kong of whom most were aged 56 to 75 years, retired, and had no history of any previous prostate surgery. Overall, the self-reported prevalence of nocturia of at least one void per night was 93\% (95\% confidence interval, 90\%-97\%), slow stream $76 \%$ (71\%-82\%), post-micturition dribble $70 \%$ (64\%-76\%), and urgency 50\% (43\%-56\%). Symptoms for which most respondents reported "some" or "a lot" of bother included: nocturia, defined as at least two voids per night (77\%), and urgency and post-micturition dribble (73\%). Only $39 \%$ to $54 \%$ of patients had previously received treatment but were not entirely satisfied with it. An understanding of their condition remained suboptimal.

Conclusions: In Hong Kong, nocturia emerged as the most prevalent and one of the most bothersome symptoms among men who sought urologist care for lower urinary tract symptoms. Compared with the non-Hong Kong population, Hong Kong respondents tended to be highly symptomatic and bothered. They were, however, less likely to have received treatment and were generally less satisfied with previous treatment.

\section{Hong Kong Med J 2017;23:562-9 \\ DOI: $10.12809 / \mathrm{hkmj} 166102$

\footnotetext{
${ }^{1}$ LY Ho *, FRCSEd (Urol), FHKAM (Surgery)

${ }^{2}$ CK Chan, FRCSEd (Urol), FHKAM (Surgery)

${ }^{3}$ PSK Chu, FRCS (Edin), FHKAM (Surgery)
}

\section{Division of Urology, Department of Surgery, Queen Elizabeth Hospital, Jordan, Hong Kong \\ Division of Urology, Department of Surgery, Prince of Wales Hospital, The Chinese University of Hong Kong, Shatin, Hong Kong Division of Urology, Department of Surgery, Tuen Mun Hospital, Tuen Mun, Hong Kong}

* Corresponding author: holapyin@yahoo.com.hk

\section{New knowledge added by this study}

Although day-time voiding symptoms have long been regarded as the more bothersome lower urinary tract symptom, results from this survey showed that nocturia was exceedingly common and could be highly bothersome to Hong Kong patients.

- Patients who presented to urologists in Hong Kong were highly symptomatic and bothered, and were less likely to have been treated before or were less satisfied with previous treatment compared with patients in other South-East Asian countries.

Implications for clinical practice or policy

- To continuously improve quality of care and accommodate an increasing service demand, there is a need to further strengthen the provision of resources and education along the continuum of care for lower urinary tract symptoms, including the primary and secondary care, for the general public and patients.

\section{Introduction}

Lower urinary tract symptoms (LUTS) collectively represent a common condition among ageing men ${ }^{1,2}$ There are limited data on the frequency of individual symptoms in patients who seek specialist care. It is well established that LUTS have far reaching impacts on patients' daily lives. ${ }^{3,4}$ There are standard tools available to assess the severity of LUTS, such as the International Prostate Symptom Score, but they do not reflect the degree to which patients are subjectively bothered by symptoms. Patient perception also depends on their cultural and 
religious background.

Treatment satisfaction and other patientreported outcomes are increasingly recognised as important measures of the effectiveness of care delivery in addition to clinical parameters. ${ }^{5}$ These measures allow health care providers to assess the quality of care that takes account of patient expectations and preferences. As more treatment options have become available, it would be of interest to assess this dimension of health care quality in patients with LUTS.

The aim of this survey was to explore SouthEast Asian patients' perception of LUTS and their treatment. Self-reported prevalence, bother, treatment, and treatment satisfaction of selected symptoms including storage (urgency, nocturia), voiding (slow stream), and post-micturition symptoms (dribble) were evaluated. In addition, patients' perception of the cause of nocturia and use of non-prescribed treatment for this symptom were explored. The study adopted a cross-sectional design and a convenience sample of patients who sought specialist care from across the region, namely Hong Kong, Malaysia, Philippines, Singapore, Thailand, and Vietnam. The study explored current unmet needs and will be used to guide the development of patientcentred management strategies. This sub-analysis evaluated data from the Hong Kong subpopulation.

\section{Methods}

\section{Subjects}

We performed a cross-sectional study in 15 urology clinics-three from Hong Kong and 12 from SouthEast Asian countries (2 from Malaysia, 2 from the Philippines, 1 from Singapore, 3 from Thailand, and 4 from Vietnam). Hong Kong data were derived from a survey of patients conducted during December 2014 to October 2015. The study involved consecutive new patients who fulfilled the following eligibility criteria: (1) male aged $\geq 18$ years who were attending the clinic for the first time, and (2) sought consultation at a urology clinic because of LUTS that had been present for at least 1 month. In this study, LUTS included increased daytime frequency, nocturia, urinary urgency, urinary incontinence, slow or weak stream, hesitancy, intermittency, straining, terminal dribble, sensation of incomplete bladder emptying, and post-micturition dribble. Such symptoms were defined according to the report from the Standardisation Sub-committee of the International Continence Society. ${ }^{6}$ Exclusion criteria were: (1) intermittent/indwelling catheterisation; (2) known prostate or bladder cancer; (3) spinal cord injury; (4) urethral stricture; (5) LUTS due to other causes, such as suspected or known urinary infection (cystitis or prostatitis); and (6) difficulty in understanding written information.

This survey involved major urology centres in

\section{有關患者對下尿路症狀及治療方法的橫斷面研} 究：在香港公共泌尿科門診部進行的意見調查

\author{
何立言、陳自覺、朱秀群
}

引言：下尿路症狀在年長男性中很常見。然而, 只有很少有關患者尋 求專科護理的數據。我們進行了一項東南亞國家的跨國調查, 針對包 括忍尿困難、夜尿、排尿緩慢及尿後餘滴的四種症狀, 評估患者對這 些症狀的比率、困擾程度、接受的治療和治療滿意度。本文集中分析 有關香港患者的數據。

方法：這橫斷面調查對象為 18 歲以上因下尿路症狀而到泌尿科診所求 診的男性。調查採用自填問卷形式進行, 該結構式問卷經當地語言翻 譯與驗證。

結果 : 共 1436 名受訪者參與是項調查, 當中 225 人來自香港。大部分 香港受訪者年齡介乎 56 歲至 75 歲、已退休以及沒有前列腺手術的病 史。總體而言, 根據受訪者填寫的資料, 每晚至少一次夜尿的比率為 93\%（95\%置信區間：90\%-97\%）、排尿緩慢76\%（71\%-82\%）、尿 後餘滴70\%（64\%-76\%）以及忍尿困難50\%（43\%-56\%）。以下是最 多受訪者感到 $「$ 有些困擾」或「非常困擾」的症狀：每晚至少兩次的 夜尿（77\%）和忍尿困難以及尿後餘滴（73\%）。受訪者中只有39\% 至54\%曾接受相關治療, 可惜並不是完全滿意治療結果。調查結果亦 顯示受訪者對症狀的了解依然不理想。

結論：在香港，因下尿路症狀而向泌尿專科求診的受訪者中，夜尿的 比率最高, 亦是最令人困擾的症狀之一。與非香港群組比較, 香港患 者有較多症狀，困擾程度也較高。然而，他們較少機會接受治療。而 且, 整體上不太滿意曾接受的治療。

South-East Asia. These centres were chosen because of two reasons: (1) they were major centres that saw 50 to 500 patients per week, and (2) there was a prior working relationship with the study group. Ethics approval from the Research Ethics Committee and Institutional Review Board were sought as required by the participating centres.

\section{Questionnaire}

A patient self-administered questionnaire was developed by the Southeast Asia Urology Think Tank that comprised a group of urology specialists. The questionnaire assessed (a) demographics (country of residence, age-group); (b) presence/absence, bother, treatment, and treatment satisfaction of each of the following symptoms: urgency, nocturia, slow stream, and post-micturition dribble; (c) perception of the cause of disease and use of non-prescribed treatment for nocturia; and (d) where appropriate, satisfaction with transurethral resection of the prostate (TURP). The questionnaire in Chinese used in Hong Kong and the original questionnaire in English are shown in the Appendices. For questions that related to the level of 'bother', responses ranged from "bother me a lot", "bother me some", "bother me a little", to "not at all bothersome". For treatment satisfaction, patients were asked to choose from the four categories: "very satisfied", "satisfied", "unsatisfied", and "very unsatisfied". 


\section{Translation and linguistic validation}

The questionnaire was translated from the original English language into traditional Chinese. The translation of the questionnaire was performed in the ethnographic mode to maintain the meaning and cultural content. The questionnaire was back translated to the original language by an independent translator for each language. The versions were compared and any major differences were reconciled. An expert in survey research and a subject expert (ie a urologist) reviewed the translations to ensure the text was accurate, equivalent to the original, written at an appropriate level (ie understood by the general public), and took account of any cultural differences. A pre-test was performed in a sample of subjects prior to distribution to the entire sample to identify and correct any issues with clarity, relevance, and comprehensiveness, as well as user-friendliness of the questionnaire. The translations were revised after the pre-test and finalised by the urologist.

\section{Data collection}

A urologist or member of the clinic staff was required to screen all consecutive new patients who presented to the urology clinic and identify potential study participants. They approached those patients who appeared eligible and explained the study to them. A patient questionnaire with an information sheet was distributed to each eligible consenting patient. Upon completion of the survey, the respondents sealed the questionnaire in an envelope and submitted it to the urologist who completed the eligibility checklist printed at the back of the questionnaire. The urologist then placed the questionnaire in an onsite lock box. Clinic staff periodically emptied the lock box and posted the contents to the data collection centre. Written informed consent was obtained from all eligible participants. To evaluate the response rate, participating centres were required to return a blank questionnaire for each eligible patient who refused to participate.

\section{Statistical analysis}

The sample size of 200 evaluable responses from each country was powered to detect a prevalence rate of $46 \%$ based on a previous study, ${ }^{6}$ with type 1 error of 0.05 and margin error not exceeding $7 \%$. We used the SPSS (Windows version 24.0; IBM Corp, Armonk [NY], US) to analyse the data. Descriptive statistics were used to calculate the prevalence of LUTS, and the distribution of participants' individual characteristics such as 'bothersome level', use of prescribed treatment, and satisfaction with specific treatments. Means and 95\% confidence intervals are reported. Categorical variables are presented as percentages and compared using Chi squared test. Association rule analysis (also known as market basket analysis) was conducted using the statistical package $\mathrm{R}$ to examine symptom combination. Cochran-Armitage trend test was used to test the trend for nocturnal voiding frequency and the level of symptom-associated bother.

\section{Results}

Between March and May 2014, a pilot survey was carried out to evaluate the applicability of the questionnaire and data collection procedure. The field test involved centres in Hong Kong, Malaysia, Philippines, Singapore, Thailand, and Vietnam. In each of these regions, the questionnaire was selfadministered by approximately 30 respondents. A total of 233 questionnaires were received from all regions: high response rates of $>90 \%$ were reported by the centres. Overall, respondents rated the questionnaire positively. The mean time taken to complete the questionnaire was 5.4 minutes.

Overall, clarity of the layout and instructions required improvement to minimise illogical/missing responses, for example, use of strong visual symbols such as arrows to direct respondents to the next question if the answer was YES/NO.

Of the 1436 questionnaires collected from all regions, 17 were deemed ineligible based on the exclusion criteria and three were blank. A total of 225 evaluable responses from Hong Kong were collated for analysis. Between December 2014 and October 2015, a total of 71 evaluable responses were collected from Prince of Wales Hospital, 65 from Queen Elizabeth Hospital and 89 from Tuen Mun Hospital.

\section{Patient characteristics}

In the Hong Kong sample, most respondents were aged 56 to 75 years $(71 \%)$, retired (54\%), and had not undergone TURP (80\%). Compared with the nonHong Kong population, Hong Kong respondents were older and more likely to have received TURP $(\mathrm{P}<0.05$; Table 1$)$.

\section{Symptom prevalence}

Among the respondents in Hong Kong who sought care at the urology clinics, LUTS were prevalent, with nocturia the most common (93\%; 95\% confidence interval [CI], 90\%-97\%), followed by slow stream (76\%; 95\% CI, 71\%-82\%), post-micturition dribble (70\%; 95\% CI, 64\%-76\%), and urgency $(50 \%$; 95\% CI, 43\%-56\%). Relative to the non-Hong Kong respondents, the prevalence was significantly higher for all four LUTS except urgency (Table 2).

A considerable number of respondents in Hong Kong reported having more than one symptom to some degree: $35 \%$ of them had all four symptoms, $32 \%$ reported three symptoms, $22 \%$ two symptoms, and only $9 \%$ a single symptom. With 
regard to symptom combinations, the strongest association was found for post-micturition dribble and co-existing urgency, nocturia, and slow stream (support: 0.353; confidence: 0.872 ; lift value: 1.249 ).

\section{Symptom bother and treatment satisfaction}

When asked to evaluate how bothersome their symptoms were, more than half of respondents in Hong Kong felt at least some degree of bother (ie "bother me some" or "bother me a lot")- $73 \%$ for urgency and post-micturition dribble, $70 \%$ for nocturia, and $68 \%$ for slow stream. When nocturia was defined as waking up twice or more at night, it became the symptom with which the most respondents reported at least some bother (77\%). The Hong Kong respondents showed a consistent trend for a higher percentage for all symptoms studied compared with the non-Hong Kong group (Table 3).

Among the respondents in Hong Kong, 39\% to $54 \%$ had received prescribed treatment. Less respondents with nocturia in Hong Kong received prescribed treatment compared with the non-Hong Kong population. The same applied to those with post-micturition dribble and urgency (Table 3 ).

More than $60 \%$ of respondents in Hong Kong reported being "satisfied" or "very satisfied" with previous prescribed treatment. Among the symptoms, the overall satisfaction rate was lower for nocturia and slow stream compared with the nonHong Kong population. Most respondents in Hong Kong (79\%-85\%) indicated they would like to receive further treatment (Table 3).

A comparison of respondents' subjective assessment of symptom bother, and outcomes of previous treatment from all regions is shown in
Table 4.

\section{Nocturia: patient perception}

Of those respondents who claimed to have nocturia, $77 \%$ reported at least two voids per night (Table 3 ). More frequent voiding was associated with a higher level of bother, ie more respondents reported "bother me some" or "bother me a lot" (Cochran-Armitage

TABLE I. Baseline demographics

\begin{tabular}{|lccc}
\hline Demographics & \multicolumn{2}{c}{ No. (\%) of respondents } & \multirow{2}{*}{ P value* } \\
\cline { 2 - 3 } & $\begin{array}{c}\text { Hong Kong } \\
\text { (n=225) }\end{array}$ & $\begin{array}{c}\text { Non-Hong Kong } \\
(\mathbf{n}=\mathbf{1 2 1 1})\end{array}$ & \\
\hline Age-group (years) & $4(2)$ & $144(12)$ & $<0.05$ \\
\hline $18-35$ & $22(10)$ & $159(13)$ & \\
$36-55$ & $160(71)$ & $660(55)$ & \\
\hline $56-75$ & $32(14)$ & $238(20)$ & \\
\hline$>75$ & $7(3)$ & $10(1)$ & $<0.05$ \\
\hline Missing data & & & \\
\hline Employment status & $80(36)$ & $410(34)$ & \\
\hline Employed & $8(4)$ & $170(14)$ & \\
\hline Not employed & $122(54)$ & $592(49)$ & \\
\hline Retired & $3(1)$ & $12(1)$ & \\
\hline Refused to answer & $12(5)$ & $27(2)$ & \\
\hline Missing data & & & \\
\hline Received TURP & $180(80)$ & $1081(89)$ & \\
\hline No & $34(15)$ & $102(8)$ & \\
\hline Yes & $11(5)$ & $28(2)$ & \\
\hline Missing data & & & \\
\hline
\end{tabular}

Abbreviation: TURP = transurethral resection of the prostate * Chi squared test

TABLE 2. Symptom prevalence

\begin{tabular}{|c|c|c|c|c|}
\hline \multirow[t]{2}{*}{ Symptom } & \multicolumn{2}{|c|}{ Hong Kong respondents } & \multicolumn{2}{|c|}{ Non-Hong Kong respondents } \\
\hline & Prevalence & $95 \% \mathrm{Cl}$ & Prevalence & $95 \% \mathrm{Cl}$ \\
\hline Urgency & $50 \%$ & $43-56$ & $53 \%$ & $50-56$ \\
\hline Base & 214 & & 1205 & \\
\hline Missing data & $11 / 225(4.9 \%)$ & & $6 / 1211(0.5 \%)$ & \\
\hline Nocturia & $93 \% *$ & $90-97$ & $87 \%$ & $85-89$ \\
\hline Base & 224 & & 1203 & \\
\hline Missing data & $1 / 225(0.4 \%)$ & & $8 / 1211(0.7 \%)$ & \\
\hline Slow stream & $76 \% *$ & $71-82$ & $58 \%$ & $55-61$ \\
\hline Base & 224 & & 1169 & \\
\hline Missing data & $1 / 225(0.4 \%)$ & & $42 / 1211(3.5 \%)$ & \\
\hline Post-micturition dribble & $70 \% *$ & $64-76$ & $52 \%$ & $49-55$ \\
\hline Base & 222 & & 1187 & \\
\hline Missing data & $3 / 225(1.3 \%)$ & & $24 / 1211(2.0 \%)$ & \\
\hline
\end{tabular}

Abbreviation: $\mathrm{Cl}=$ confidence interval

* $\mathrm{P}<0.05$, significantly higher than the non-Hong Kong population 
TABLE 3. Comparison of subjective assessment of symptom bother and outcomes of previous treatment between Hong Kong and non-Hong Kong respondents

\begin{tabular}{|c|c|c|}
\hline & $\begin{array}{l}\text { Hong Kong } \\
\text { respondents }\end{array}$ & $\begin{array}{l}\text { Non-Hong Kong } \\
\text { respondents }\end{array}$ \\
\hline \multicolumn{3}{|c|}{$\begin{array}{l}\text { Symptom bother (\% of patients who reported the symptom "bother me some" or } \\
\text { "bother me a lot") }\end{array}$} \\
\hline Urgency & $73 \% *$ & $61 \%$ \\
\hline Base & 98 & 705 \\
\hline Nocturia ( $\geq 1$ void/night) & $70 \%{ }^{*}$ & $57 \%$ \\
\hline Base & 200 & 1211 \\
\hline Nocturia ( $\geq 2$ voids/night) & $77 \%{ }^{*}$ & $61 \%$ \\
\hline Base & 154 & 826 \\
\hline Slow stream & $68 \%{ }^{*}$ & $58 \%$ \\
\hline Base & 158 & 804 \\
\hline Post-micturition dribble & $73 \%{ }^{*}$ & $60 \%$ \\
\hline Base & 146 & 710 \\
\hline \multicolumn{3}{|c|}{$\begin{array}{l}\text { Received prescribed treatment before consulting the current urologist (\% of } \\
\text { patients answered "Yes") } \ddagger\end{array}$} \\
\hline Urgency & $39 \% \dagger$ & $57 \%$ \\
\hline Base & 96 & 597 \\
\hline Nocturia & $50 \% \dagger$ & $58 \%$ \\
\hline Base & 193 & 952 \\
\hline Slow stream & $54 \%$ & $59 \%$ \\
\hline Base & 155 & 663 \\
\hline Post-micturition dribble & $41 \% \dagger$ & $53 \%$ \\
\hline Base & 146 & 572 \\
\hline
\end{tabular}

Satisfaction with previous prescribed treatment (\% of patients reporting being "satisfied" or "very satisfied")

\begin{tabular}{clc} 
Urgency & $68 \%$ & $74 \%$ \\
Base & 38 & 343 \\
\hline Nocturia & $66 \% \dagger$ & $80 \%$ \\
Base & 92 & 553 \\
\hline Slow stream & $62 \% \dagger$ & $78 \%$ \\
Base & 81 & 390 \\
\hline Post-micturition dribble & $67 \%$ & $75 \%$ \\
Base & 57 & 311
\end{tabular}

Intention to receive further treatment (\% of patients answered "Yes")

\begin{tabular}{|ccc|}
\hline Urgency & $82 \%$ & $85 \%$ \\
\hline Base & 72 & 292 \\
\hline Nocturia & $85 \%$ & $78 \%$ \\
\hline Base & 117 & 541 \\
\hline Slow stream & $84 \%$ & $86 \%$ \\
Base & 101 & 328 \\
\hline Post-micturition dribble & $79 \%$ & $84 \%$ \\
\hline Base & 102 & 323 \\
\hline
\end{tabular}

\footnotetext{
* $\mathrm{P}<0.05$, significantly higher than the non-Hong Kong population

+ $P<0.05$, significantly lower than the non-Hong Kong population

‡ Excluding patients who answered "don't know"
}

trend test, $\mathrm{Z}=-5.3044, \mathrm{P}<0.0001$; Fig). More than half $(53 \%)$ of respondents regarded the prostate as the main cause of nocturia, and 39\% answered "don't know". Some respondents (17\%) had taken nonprescribed treatment for nocturia, including herbal medicines and supplements.

\section{Symptom improvement after transurethral resection of the prostate}

Only a small proportion (15\%) of respondents had previously undergone TURP. More than half of respondents reported improved symptoms following surgery (Table 5). The small number of respondents and occurrence of multiple symptoms in individual respondents made it difficult to compare the improvement rates across symptoms.

\section{Discussion}

\section{Symptom profiles of respondents}

The survey provided information on the characteristics of men with LUTS who attended urology clinics in Hong Kong. The respondents were mostly elderly, retired, and had not undergone any prostate surgery. The most commonly reported symptoms were nocturia and slow stream. Almost $80 \%$ of respondents with nocturia awoke at least twice per night to void. This was by far the most bothersome symptom followed by daytime symptoms, urgency, and post-micturition dribble. This finding is in line with results from previous studies conducted in a primary care setting that reported nocturia as a significant driving factor to trigger medical consultations. ${ }^{7,8}$ Nocturia could be highly bothersome to patients. Waking during the night to void disrupts sleep for both the patient and their partner, and impaired sleep is known to affect quality of life. We also established that LUTS often co-exist, and are in line with the EpiLUTS in Korea9 and Europe. ${ }^{10}$ In this study, the association rules analysis further revealed that in the local population, for respondents with urgency, slow stream and nocturia, there was an $87 \%$ risk of co-existing postmicturition dribble.

\section{Respondent's perception of bother and satisfaction with previous treatment}

The survey findings help identify patient needs by exploring respondents' perceived degree of bother and treatment satisfaction. Compared with the nonHong Kong population, Hong Kong respondents tended to report a higher level of symptom bother (approximately 70\% experiencing "some" or "a lot" bother), were less likely to have received prescribed treatment before consulting the current urologist, and reported lower treatment satisfaction. This could be due to several reasons: (1) cultural differences in patient perception of the symptom bother and their treatment expectation; (2) higher referral threshold for primary care practitioners in Hong Kong; (3) more conservative practice of primary care 
TABLE 4. Comparison of subjective assessment of symptom bother and outcomes of previous treatment among all regions

\begin{tabular}{|c|c|c|c|c|c|c|c|}
\hline & Overall & Hong Kong & Malaysia & Philippines & Singapore & Thailand & Vietnam \\
\hline \multicolumn{8}{|c|}{ Symptom bother (\% of patients who reported the symptom "bother me some" or "bother me a lot") } \\
\hline Urgency & $61 \%$ & $73 \% *$ & $51 \%$ & $50 \% \dagger$ & $47 \%$ & $53 \%$ & $71 \%{ }^{*}$ \\
\hline Base & 705 & 98 & 102 & 105 & 32 & 118 & 250 \\
\hline Nocturia ( $\geq 1$ void/night) & $57 \%$ & $70 \% *$ & $56 \%$ & $55 \%$ & $34 \% \dagger$ & $39 \% \dagger$ & $72 \% *$ \\
\hline Base & 1211 & 200 & 153 & 183 & 87 & 262 & 326 \\
\hline Nocturia ( $\geq 2$ voids/night) & $63 \%$ & $77 \%$ * & $59 \%$ & $59 \%$ & $40 \% \dagger$ & $43 \% \dagger$ & $82 \% *$ \\
\hline Base & 980 & 154 & 134 & 160 & 58 & 213 & 261 \\
\hline Slow stream & $57 \%$ & $68 \% *$ & $67 \%$ & $53 \%$ & $26 \% \dagger$ & $48 \% \dagger$ & $61 \%$ \\
\hline Base & 804 & 158 & 83 & 107 & 53 & 174 & 229 \\
\hline Post-micturition dribble & $60 \%$ & $73 \%{ }^{*}$ & $63 \%$ & $57 \%$ & $38 \% \dagger$ & $47 \% \dagger$ & $63 \%$ \\
\hline Base & 710 & 146 & 91 & 87 & 42 & 133 & 211 \\
\hline \multicolumn{8}{|c|}{ Received prescribed treatment before consulting the current urologist (\% of patients who reported "Yes") } \\
\hline Urgency & $54 \%$ & $39 \% \dagger$ & $81 \% *$ & $55 \%$ & $48 \%$ & $78 \% *$ & $40 \% \dagger$ \\
\hline Base & 715 & 102 & 103 & 109 & 32 & 114 & 255 \\
\hline Nocturia & $57 \%$ & $50 \%$ & $86 \% *$ & $57 \%$ & $43 \% †$ & $77 \% *$ & $38 \% \dagger$ \\
\hline Base & 1213 & 199 & 154 & 171 & 86 & 266 & 337 \\
\hline Slow stream & $57 \%$ & $50 \%$ & $93 \% *$ & $60 \%$ & $46 \% †$ & $69 \%$ & $42 \% \dagger$ \\
\hline Base & 827 & 167 & 84 & 128 & 52 & 171 & 225 \\
\hline Post-micturition dribble & $49 \%$ & $39 \% \dagger$ & $78 \% *$ & $51 \%$ & $29 \% \dagger$ & $66 \%$ & $36 \% \dagger$ \\
\hline Base & 744 & 153 & 92 & 106 & 42 & 137 & 214 \\
\hline \multicolumn{8}{|c|}{ Satisfaction with previous prescribed treatment (\% patients who reported "satisfied" or "very satisfied") } \\
\hline Urgency & $74 \%$ & $69 \%$ & $86 \% *$ & $82 \% *$ & $93 \%{ }^{*}$ & $99 \%$ & $38 \% \dagger$ \\
\hline Base & 373 & 36 & 83 & 55 & 15 & 82 & 102 \\
\hline Nocturia & $78 \%$ & $66 \% \dagger$ & $90 \% *$ & $87 \% *$ & $94 \% *$ & $98 \% *$ & $35 \% \dagger$ \\
\hline Base & 640 & 92 & 130 & 93 & 35 & 168 & 122 \\
\hline Slow stream & $75 \%$ & $62 \% \dagger$ & $91 \% *$ & $86 \% *$ & $83 \% *$ & $97 \%$ & $36 \% \dagger$ \\
\hline Base & 466 & 81 & 79 & 73 & 24 & 116 & 93 \\
\hline Post-micturition dribble & $74 \%$ & $67 \% \dagger$ & $89 \% *$ & $70 \%$ & $83 \%{ }^{*}$ & $98 \%{ }^{*}$ & $41 \% \dagger$ \\
\hline Base & 360 & 57 & 72 & 54 & 12 & 89 & 76 \\
\hline \multicolumn{8}{|c|}{ Intention to receive further treatment (\% of patients who reported "Yes") } \\
\hline Urgency & $85 \%$ & $82 \%$ & $86 \%$ & $66 \% \dagger$ & $61 \% \dagger$ & $69 \% \dagger$ & $97 \% *$ \\
\hline Base & 364 & 72 & 29 & 53 & 18 & 29 & 163 \\
\hline Nocturia & $80 \%$ & $86 \% *$ & $74 \%$ & $78 \%$ & $50 \% \dagger$ & $51 \% \dagger$ & $95 \% *$ \\
\hline Base & 658 & 117 & 46 & 89 & 52 & 97 & 257 \\
\hline Slow stream & $85 \%$ & $84 \%$ & $82 \%$ & $79 \% \dagger$ & $69 \% \dagger$ & $64 \% \dagger$ & $97 \% *$ \\
\hline Base & 409 & 101 & 11 & 53 & 32 & 50 & 162 \\
\hline Post-micturition dribble & $83 \%$ & $79 \%$ & $67 \% \dagger$ & $77 \%$ & $47 \% \dagger$ & $77 \% \dagger$ & $99 \% *$ \\
\hline Base & 422 & 102 & 27 & 64 & 32 & 44 & 153 \\
\hline
\end{tabular}

* $\mathrm{P}<0.05$, significantly higher compared with overall results

$+\mathrm{P}<0.05$, significantly lower compared with overall results

physicians (eg more use of watchful waiting); and place in Hong Kong. A greater involvement of the (4) a longer waiting time to access urology specialty primary care sector in the management of LUTS is services. believed to allow a more rational use of resources as

One distinguishing feature of the Hong Kong a result of reduced time spent on waiting lists, earlier health care system from other participating countries therapy, and increased access to specialist services is that a primary care physician referral system is in for those in need of extensive investigations or 


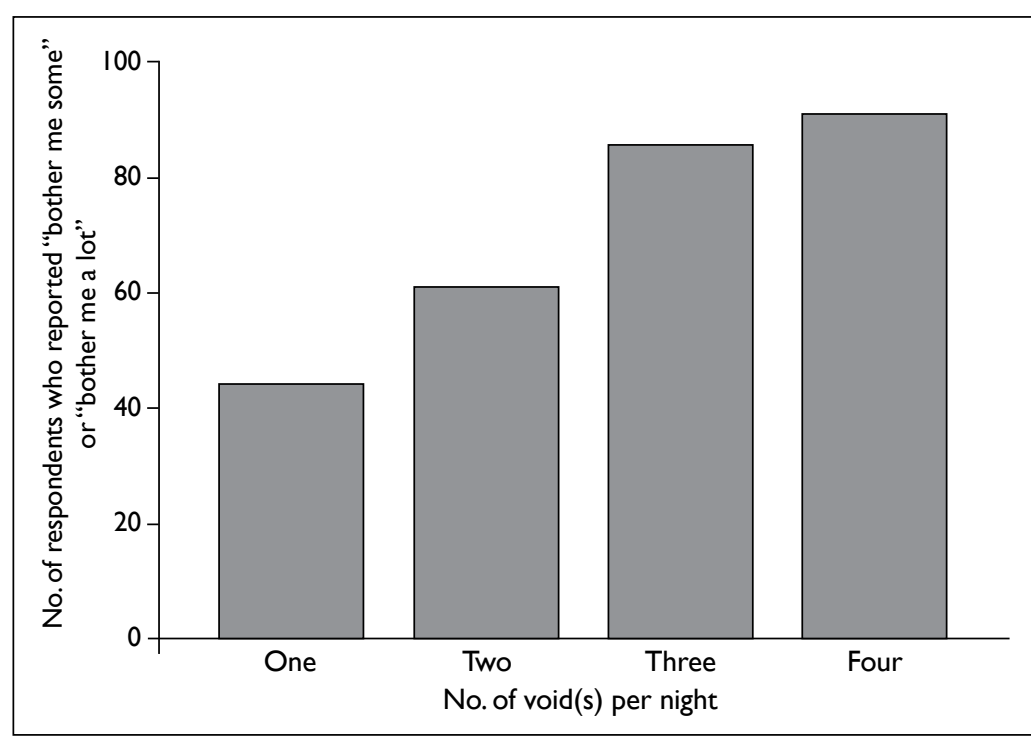

FIG. Nocturnal voiding frequency and bother experienced by patients

TABLE 5. Symptom improvement in the Hong Kong study population after transurethral resection of the prostate

\begin{tabular}{llcc}
\hline Symptom & Improved & Not improved & Worse \\
\hline Urgency & $78 \%$ & $22 \%$ & $0 \%$ \\
Base & 23 & - & - \\
Nocturia & $52 \%$ & $29 \%$ & $19 \%$ \\
Base & 31 & - & - \\
Slow stream & $52 \%$ & $39 \%$ & $9 \%$ \\
Base & 23 & - & - \\
Post-micturition dribble & $60 \%$ & $35 \%$ & $5 \%$ \\
Base & 20 & - & - \\
\hline
\end{tabular}

surgery. ${ }^{11}$ In this sense, it is understandable that it is those mostly highly symptomatic patients who have failed medical therapy are referred to urologists. Intriguingly, fewer respondents in Hong Kong than in other South-East Asian countries reported being given prescribed treatment, suggesting that primary care physicians adopt a more conservative approach to the treatment of LUTS, although this remains to be confirmed with findings from medical records.

Local data are limited whereas overseas studies showed that primary care physicians are more likely to engage in watchful waiting than urologists. Fewer men received recommended diagnostic evaluations from primary care physicians than from urologists, such as uroflowmetry, bladder scans, and cystoscopy. Primary care physicians ordered tests such as creatinine measurement that are less frequently used by urologists. Primary care physicians were also more likely to prescribe an older, long-acting alpha blocker that requires dose titration, and less likely to prescribe combination therapy such as 5-alpha- reductase inhibitor and anticholinergic therapy. ${ }^{12,13}$ Interdisciplinary care plans, detailed inter-physician referral and consultation letters, and integrated clinics have been suggested to improve physician communication and patient care. ${ }^{14,15}$

Satisfaction with care is an important outcome. It is multidimensional, comprising satisfaction with the care process and with care outcomes, and involves the patient's personality and expectations and the health care provider's interpersonal skills as well as technical excellence. The components of the care process may include waiting times, provision of information, access to care, adequacy of care environment, and speed of treatment. The other major element of the satisfaction domain concerns care outcome. Individuals whose outcome is either below personal expectations or who experience treatment side-effects may be less satisfied with the care they have received. ${ }^{16}$

\section{Respondents' understanding of lower urinary tract symptoms}

In terms of the cause of nocturia, $39 \%$ of respondents responded "don't know" and 53\% regarded the prostate as the primary cause. This indicates a need for more education and better physician-patient communication. Surveys conducted in Korea and Europe showed that it is the complications of LUTS more than the actual symptoms with which respondents are most concerned. ${ }^{17,18}$ Because primary care physicians are usually the first point of medical contact for men with LUTS, they can play an important role in educating patients and diagnosing the condition. ${ }^{13}$

\section{Study strengths and limitations}

This is a large-scale multinational study that assesses LUTS and their treatment from the patients' perspective at a secondary care level. Our study had several limitations. First, the subjects surveyed were patients who were bothered by their symptoms and who sought a urology opinion and agreed to participate in this study. Results of this self-administered survey were subject to recall bias, for examples, about medication received, number of voids at night, and quality of treatment received from their previous physicians. Further study is required to explore an association with clinical assessment. Second, convenience sampling limited the representativeness of the study sample. Third, the response rates of this study were estimated by the number of blank questionnaires returned; each of which indicated a refusal to participate. Centres might not follow this closely in practice and the reasons for non-participation were not recorded. This may have introduced potential response bias. Fourth, missing data are attributed to the involvement of older adults in this survey. Fifth, 
following the completion of the pilot survey, the questionnaire was later revised to improve clarity of the layout and instructions to minimise illogical/ missing responses, for example, use of strong visual symbols such as arrows to direct respondents to the next question if the answer is YES/NO. Lastly, the questionnaires included only four predominant LUTS. Although these core symptoms are the main factors in the assessment of LUTS, it is possible that lack of assessment of other symptoms limited our understanding of all LUTS symptomatology. When interpreting the results, it is important to take into account the differences among cities/countries, referral systems, waiting list times, and socioeconomic composition of the samples.

\section{The way forward}

The demand for specialist care in the management of LUTS is expected to rise with increasing lifeexpectancy. Currently, TURP is the most common elective surgery in Hong Kong-about 3000 operations are performed at hospitals managed by the Hospital Authority each year. ${ }^{19}$ To keep pace with the increasing patient load and to improve the quality of care, findings from this study call for better streamlining of the shared-care model between general practitioners and urologists. More resources are required that will enable increased access to urology specialty services. This study provides an insight into the overall patient satisfaction with previous treatment before presentation to a specialist clinic. A complete evaluation of health care quality that examines different dimensions-such as structure, process, and quality of care-is warranted.

\section{Conclusions}

The survey provided much-needed information about patient perspectives regarding symptoms, bother, and treatment of LUTS. There is room for improvement in the quality of care provided to LUTS patients.

\section{Appendices}

Additional material related to this article can be found on the HKMJ website. Please go to <http:// www.hkmj.org>, and search for the article.

\section{Declaration}

All authors have disclosed no conflicts of interest.

\section{References}

1. Yee CH, Li JK, Lam HC, Chan ES, Hou SS, Ng CF. The prevalence of lower urinary tract symptoms in a Chinese population, and the correlation with uroflowmetry and disease perception. Int Urol Nephrol 2014;46:703-10.

2. Wong SY, Woo J, Hong A, Leung JC, Kwok T, Leung PC. Risk factors for lower urinary tract symptoms in southern
Chinese men. Urology 2006;68:1009-14.

3. Glover L, Gannon K, McLoughlin J, Emberton M. Men's experiences of having lower urinary tract symptoms: factors relating to bother. BJU Int 2004;94:563-7.

4. Gannon K, Glover L, O’Neill M, Emberton M. Lower urinary tract symptoms in men: self-perceptions and the concept of bother. BJU Int 2005;96:823-7.

5. Abrams P, Andersson KE, Birder L, etal. Fourth International Consultation on Incontinence Recommendations of the International Scientific Committee: evaluation and treatment of urinary incontinence, pelvic organ prolapse, and fecal incontinence. Neurourol Urodyn 2010;29:213-40.

6. Li MK, Garcia LA, Rosen R. Lower urinary tract symptoms and male sexual dysfunction in Asia: a survey of ageing men from five Asian countries. BJU Int 2005;96:1339-54.

7. Abrams P, Cardozo L, Fall M, et al. The standardisation of terminology in lower urinary tract function: report from the standardisation sub-committee of the International Continence Society. Urology 2003;61:37-49.

8. Lai UC, Wun YT, Luo TC, Pang SM. In a free healthcare system, why do men not consult for lower urinary tract symptoms (LUTS)? Asia Pac Fam Med 2011;10:7.

9. Kim TH, Han DH, Lee KS. The prevalence of lower urinary tract symptoms in Korean men aged 40 years or older: a population-based survey. Int Neurourol J 2014;18:126-32.

10. Irwin DE, Milsom I, Hunskaar S, et al. Population-based survey of urinary incontinence, overactive bladder, and other lower urinary tract symptoms in five countries: results of the EPIC study. Eur Urol 2006;50:1306-14; discussion 1314-5.

11. Fonseca J, Martins da Silva C. The diagnosis and treatment of lower urinary tract symptoms due to benign prostatic hyperplasia by primary care family physicians in Portugal. Clin Drug Investig 2015;35(Suppl 1):19-27.

12. Spatafora S, Canepa G, Migliari R, et al. Effects of a shared protocol between urologists and general practitioners on referral patterns and initial diagnostic management of men with lower urinary tract symptoms in Italy: the Prostate Destination study. BJU Int 2005;95:563-70.

13. Miner MM. Primary care physician versus urologist: how does their medical management of LUTS associated with BPH differ? Curr Urol Rep 2009;10:254-60.

14. Lopéz BM, Romero AH, Ortín EO, Garcia IL. Can primary care physicians manage benign prostatic hyperplasia patients as urologists do? Eur Med J Urol Jul 2014:1-8.

15. Wei JT, Miner MM, Steers WD, et al. Benign prostate hyperplasia evaluation and management by urologists and primary care physicians: practice patterns from the observational BPH Registry. J Urol 2011;186:971-6.

16. Roehrborn CG, Nuckolls JG, Wei JT, Steers W; BPH Registry and Patient Survey Steering Committee. The benign prostatic hyperplasia registry and patient survey: study design, methods and patient baseline characteristics. BJU Int 2007;100:813-9.

17. George AK, Sandra MG. Measuring patient satisfaction. In: Penson DF, Wei JT, editors. Clinical research methods for surgeons. New Jersey: Humana Press; 2006: 253-65.

18. Kim SI, Kang JY, Lee HW, Seong do H, Cho JS. A survey conducted on patients' and urologists' perceptions of benign prostatic hyperplasia. Urol Int 2011;86:278-83.

19. Leung KK, So HS. Evolution of care for patients undergoing transurethral resection of prostate. Available from: https:// www3.ha.org.hk/haconvention/hac2014/proceedings/ downloads/SPPE559.pdf. Accessed 16 May 2016. 